\title{
Hidden invasion and niche contraction revealed by herbaria specimens in the fungal complex causing oak powdery mildew in Europe
}

\author{
Andrin Gross (iD - Célia Petitcollin • Cyril Dutech • Bayo Ly • Marie Massot • \\ Julie Faivre d'Arcier • Laure Dubois • Gilles Saint-Jean • Marie-Laure Desprez-Loustau (i)
}

Received: 11 June 2020/ Accepted: 28 October 2020/Published online: 4 December 2020

(C) The Author(s) 2020

\begin{abstract}
Deciphering the dynamics involved in past microbial invasions has proven difficult due to the inconspicuous nature of microbes and their still poorly known diversity and biogeography. Here we focus on powdery mildew, a common disease of oaks which emerged in Europe at the beginning of the twentieth century and for which three closely related Erysiphe species are mainly involved. The study of herbaria samples combined with an experimental approach of interactions between Erysiphe species led us to revisit the history of this multiple invasion. Contrary to what was previously thought, herbaria sample analyses very strongly suggested that the currently dominant species, E. alphitoides, was not the species which caused the first outbreaks and was described as a new species
\end{abstract}

Electronic supplementary material The online version of this article (https://doi.org/10.1007/s10530-020-02409-z) contains supplementary material, which is available to authorized users.

A. Gross $(\bowtie) \cdot$ C. Petitcollin · C. Dutech .

B. Ly · M. Massot · J. Faivre d'Arcier .

L. Dubois · G. Saint-Jean · M.-L. Desprez-Loustau

BIOGECO, INRAE, University of Bordeaux,

33610 Cestas, France

e-mail: andrin.gross@wsl.ch

A. Gross

Biodiversity and Conservation Biology, Swiss Federal

Research Institute for Forest, Snow and Landscape

Research WSL, Zürcherstrasse 111, 8903 Birmensdorf,

Switzerland at that time. Instead, E. quercicola was shown to be present since the early dates of disease reports and to be widespread all over Europe in the beginning of the twentieth century. E. alphitoides spread and became progressively dominant during the second half of the twentieth century while E. quercicola was constrained to the southern part of its initial range, corresponding to its current distribution. A competition experiment provided a potential explanation of this over-invasion by demonstrating that E. alphitoides had a slight advantage over E. quercicola by its ability to infect leaves during a longer period during shoot development. Our study is exemplary of invasions with complexes of functionally similar species, emphasizing that subtle differences in the biology of the species, rather than strong competitive effects may explain patterns of over-invasion and niche contraction.

Keywords Ontogenic resistance - Competition · Reproductive interference - Mating type - Overinvasion $\cdot$ Forest pathogen

\section{Introduction}

The microbial component of biological invasions has been recognized rather lately compared to plant and animal invasions (Desprez-Loustau et al. 2007; Mallon et al. 2015; Dunn and Hatcher 2015; Blackburn and Ewen 2017). However, the dramatic impact of diseases caused by pathogens of exotic origin in 
natural communities is well documented (Hatcher et al. 2012; Fisher et al. 2012). For example, the spread of the fungus Batrachochytrium dendrobatidis, which causes chytrid disease, has been shown to be a key factor in the worldwide decline of amphibian populations (Fisher et al. 2009). The global emergence of invasive microbial pathogens is now considered a major challenge in invasion science (Ricciardi et al. 2017). Microbes are characterized by a tremendous diversity, harboring still numerous undescribed species. In particular, the fungal kingdom has been estimated to include several millions of species, of which only a few percent have been formally described (Blackwell 2011; Hawksworth and Lücking 2017; Wu et al. 2019). The lack of diagnostic features for species identification before the advent of molecular and phylogenetic methods explains that many species, only defined on a morphological basis, were thought to be cosmopolitan (Taylor et al. 2000). The recognition of cryptic species within morphological species has now become extremely common (Fitt et al. 2006; Crous et al. 2016). Cryptic species often show a different geographic distribution, ecology and pathogenicity (Taylor et al. 2000). For example, the recent ash dieback observed in Europe, which was initially thought to be caused by the native species Hymenoscyphus albidus, was shown to be associated with a closely related and morphologically almost indistinguishable species of Asian origin. $H$. fraxineus has probably co-evolved with Asian ash, on which it causes little damage (Gross et al. 2014; Enderle et al. 2019). The introduced species $H$. fraxineus has now spread in almost the whole range of ash in Europe and has progressively outcompeted the native species, $H$. albidus, which can hardly be found in areas where the new disease has been reported (McKinney et al. 2012; but see Dvorak et al. 2015; Koukol et al. 2015).

With increasing rates of introductions, invasions may involve not only interactions between native and introduced species but also between introduced species in the same area. Multiple or successive invasions by functionally equivalent or closely related species have started to be documented and investigated, especially in plants and animals (Rauschert and Shea 2012; Russell et al. 2014; Linzmaier et al. 2018). Many examples of multiple invasions have been reported for insects (Reitz and Trumble 2002). It may be hypothesized that such multiple invasions could also be very frequent for microbial pathogens which, similar to insects, show a great diversity, including complexes of cryptic species, and propensity to be disseminated with human activities. The two successive pandemics of Dutch Elm Disease, caused by the spread of two fungal species (Ophiostoma ulmi and Ophiostoma novo-ulmi) outside their native area, is one among very few documented examples for fungi (Brasier and Buck 2001) but the availability of molecular methods may increasingly reveal the high significance of multiple microbial invasions. Multiple invasion events are interesting to address important questions in ecology, e.g. species coexistence or displacement. Historically, species displacements, intimately linked to invasions, have been considered as an illustration of competitive exclusion, where the most competitive species eliminates the other species sharing the same ecological niche (DeBach 1966; Gao and Reitz 2017). However, the outcome of competitive interactions during invasions may not be as extreme, depending on the amount of niche overlap, the relative competitive ability of species for resource use, and spatial and temporal variations in the interaction (MacDougall et al. 2009; Gao and Reitz 2017). In the case of Dutch Elm Disease, the fitness advantage of $O$. novo-ulmi, which eventually displaced O. ulmi, was shown to include several components, such as direct competitive antagonism, exploitative competition through resource use and wider climatic niche (Brasier and Buck 2001). Considering cryptic species in invasions has also important practical implications. The fact that many microbial, including fungal, pathogens occur as species complexes may impede the detection of a new, potentially more damaging, introduced pathogen if a closely related species causing the same symptoms has already invaded. Ash dieback, but also grapevine powdery mildew in Europe are examples of diseases caused by an introduced pathogen species having close relatives in its native area, which constitute further risks for the target host species (Schröder et al. 2011; Gross and Han 2015).

Here, we focus on a complex of closely related fungi causing the same tree disease: Erysiphe spp, causing oak powdery mildew. Among the seven species in this clade, probably native to Asia (Takamatsu et al. 2007), three have been introduced in Europe (see history of introductions in Mougou et al. 2008). E. alphitoides was the first reported and described, after the emergence of severe epidemics 
at the beginning of the twentieth century. The pathway of invasion of E. alphitoides remains unknown. The disease was widespread all over Europe within a few years. E. hypophylla, with a slightly different morphology and disease symptoms, was first reported in the 1960 's, after a putatively independent introduction, and showed a North-East to South-West spread (Viennot-Bourgin 1968). Finally, E. quercicola has only been detected recently in Europe when molecular markers were available for species identification. Its date of introduction therefore remains undetermined. A fourth oak powdery mildew species, in another genus (Phyllactinia roboris), is very rarely found in contemporary samples and might represent a native species, which was replaced by invasive species (Desprez-Loustau et al. 2011). The current distribution of the three Erysiphe species in Europe, although different, shows overlap at different spatial scales, from the leaf to the continent (Desprez-Loustau et al. 2018). This pattern of coexistence suggested that niche differences, both temporal (Feau et al. 2012; Hamelin et al. 2016) and spatial (Desprez-Loustau et al. 2018), rather than competitive interactions shaped the distribution of these species.

The aim of the present study was to improve our understanding of the multiple invasion of oak powdery mildew fungi in Europe. By using more than 200 herbarium specimens of infected oak leaves, dating from 1875 to 2002 and distributed all over Europe, our first goal was to date the invasion history of the three species. Next, we tried to elucidate potential processes underlying the observed invasion dynamics by investigating two mechanisms possibly responsible for invasive success (i) the mating type ratio, conditioning sexual reproduction, characterized in the herbaria specimens for E. alphitoides and E. quercicola and (ii) competitive interactions between the two species, using an experimental approach with fresh isolates.

\section{Materials and methods}

Herbaria specimens

Specimens were obtained from six mycological collections: University Paul Sabatier of Toulouse (France), Fungarium Z + ZT, ETH Zurich, Switzerland, forest pathogen collection of the forest protection service of Switzerland, Swiss Federal Institute of
Forest, Snow and Landscape Research WSL (Birmensdorf, Switzerland), Royal Botanical Gardens Fungarium (Kew, Richmond, United Kingdom), Botanische Staatssammlung Munich (Munich, Germany), Natural History Museum in Kopenhagen (Denmark).

We tried to obtain as many specimens as possible from all over Europe collected between late nineteenth century and 1980 consisting of leaves infected by oak powdery mildew, recorded under different names, most often Microsphaera alphitoides, but also Erysiphe quercina or others (Online Resource 2).

\section{Molecular identification of species}

Specimens were examined under a binocular microscope for the presence of conidia and chasmothecia (sexual stage). The presence of the latter was specifically noted and is reported in Online Resource 2. For each specimen, one small piece of leaf (approx. $1 \mathrm{~cm}^{2}$ ) was cut from a zone with conidia using a sterilized scalpel. The leaf pieces were put in Eppendorf tubes ( $2 \mathrm{~mL}$ ) with two steel beads (4 mm diameter) and approximately $75 \mathrm{mg}$ of white quartz sand to improve grinding. Grinding was made with a Grinder Shaker Pulverizer Tissuelyser (Retsch MM 300) during $30 \mathrm{~s}$ at $30 \mathrm{~Hz}$. DNA extraction was carried out with the Invisorb ${ }^{\circledR}$ Spin Plant Mini Kit (STRATEC Molecular $\mathrm{GmbH}$, Berlin, Germany), according to manufacturer's instructions. Species identification was based on PCR amplification and Sanger sequencing of the ITS region, as previously described for contemporary samples (Mougou-Hamdane et al. 2010; DesprezLoustau et al. 2018). Protocols were, however, slightly modified to obtain sufficient quantities of DNA from old samples, by using $4 \mu \mathrm{l}$ instead of $2 \mu \mathrm{l}$ undiluted DNA for the PCR and extending the number of cycles to up to 45 (instead of 35). Positive (DNA from contemporary samples) and negative (water) samples were included at all steps. The homology of sequences with E. alphitoides, E. hypophylla or E. quercicola was verified by nBLAST analysis (https://blast.ncbi. nlm.nih.gov/Blast.cgi), using the reference Genbank sequences AB292708, AB292716 and AB193591, respectively (Takamatsu et al. 2007). Identification of species within this complex, including mixtures, was possible thanks to six diagnostic SNPs in the amplified region, with specific alleles fixed in each species (three 
SNPs for each species pair comparison) (MougouHamdane et al. 2010; Desprez-Loustau et al. 2018).

Determination of mating types

Most powdery mildews studied so far have been shown to be heterothallic. In this case, sexual reproduction (leading to the production of chasmothecia, the ascocarps) is only possible if the two mating individuals have different sequences at the MAT1 locus, called the MAT1-1 and MAT1-2 idiomorphs (Brewer et al. 2011). In order to characterize the frequency of the mating types in the herbaria samples, primers were developed for partial regions of the two genes MAT11-1 and MAT1-2-1, corresponding to the two mating types MAT1-1 and MAT1-2, by using the Primer3 software Release 4.1.0 (Untergasser et al. 2012; http:// primer3.ut.ee/). A sequence of the MAT1-1-1 gene was available for E. alphitoides and E. quercicola from whole genome sequencing of two strains of these species (Dutech et al. 2020). For MAT1-2-1, sequences of closely related species (Erysiphe necator, E. pisi, Blumeria graminis), retrieved from Genbank (https:// www.ncbi.nlm.nih.gov/genbank/) were used. After import in the Geneious11.0.4 software and alignment with ClustalW, several primer pairs for each idiomorph (targeting both E. alphitoides and E. quercicola) were designed to amplify fragments of 120-250 bp. These primer pairs were tested on contemporary mono-spore isolates of E. alphitoides and E. quercicola, using a standard PCR protocol. Amplicons were sequenced by Sanger sequencing (GENEWIZ, Leipzig, Germany). The primer pairs for the initial MAT1 amplification of E. quercicola, E. alphitoides and E. hypophylla were the following for the MAT1-1-1 gene at the MAT1-1 idiomorph: Ea-Mat111F = 5'-TTA-TTT-CTG-CGGCGT-ACT-CA-3' (forward), Ea-Mat111R = 5'-ACCCCT-TTC-AGC-ACA-AAA-CA-3' (reverse); and for the MAT1-2-1 gene at the MAT1-2 idiomorph: mat1$2-\mathrm{F}=5$ ' -CGA-AAR-AGT-AAA-CAT-GCC-GAWAC-3' (forward), mat1-2-R2 = 5' -CTT CAG AAG ATT TCC GYG GTC-3' (reverse). Representative sequences of both mating types of the tree species were deposited in GenBank (accession numbers, MT592825 - MT592842). We checked by PCR amplification that a single idiomorph was detected in mono-spore isolates (results not shown), supporting heterothallism in E. alphitoides and E. quercicola, as generally reported for powdery mildew fungi. After preliminary tests on herbaria samples, we selected one pair of primers for each mating type corresponding to amplicons of short sizes $(<150 \mathrm{bp})$ to optimize the probability of detection of these single copy genes in ancient DNA. The primer pairs finally selected were the following for the MAT1-1 idiomorph: mat1$\mathrm{F}=5^{\prime}$ - TTC-TGC-GGC-GTA-CTC-AAA-GA-3' (forward), mat1-R = 5'-GCT-CCA-GTT-AAG-CAAAGG-AAG-G-3' (reverse, generating an amplicon of $132 \mathrm{bp}$ ); and for the MAT1-2 idiomorph: mat2-F = 5' CGA-AAG-AGT-AAA-CAT-GCC-GAT-AC-3' (forward), mat2-R = 5'-GCC-CAC-ATA-CGA-GCGATT-AG-3' (reverse, generating an amplicon of $134 \mathrm{bp}$ ). The reaction mixtures for PCR had a total volume of $21 \mu \mathrm{l}$ and contained $2 \mu \mathrm{l}$ of pure genomic DNA, $2 \mu \mathrm{L}$ of 10X PCR buffer (Ozyme ref. OZYA001), $0.8 \mu \mathrm{L}$ of a mixture of $5 \mathrm{mM}$ dNTPs (EUROBIO ref GAEPCR11-5D), $0.5 \mu \mathrm{L}$ of each primer $(1 \mu \mathrm{M}), 1.2 \mu \mathrm{L}$ of $25 \mathrm{mM} \mathrm{MgCl} 2,0.1 \mu \mathrm{L}$ of BSA $(10 \mathrm{mg} / \mathrm{ml}$, Sigma) and $0.1 \mu \mathrm{L}$ of Taq polymerase $5 \mathrm{U} /$

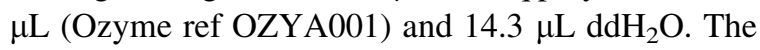
amplification reactions were done on a Veriti Thermal Cycler (Applied Biosystems). The PCR included an initial denaturation at $94{ }^{\circ} \mathrm{C}$ for $3 \mathrm{~min}$, followed by 40 cycles of denaturation at $94{ }^{\circ} \mathrm{C}$ for $30 \mathrm{~s}$, hybridization at $59{ }^{\circ} \mathrm{C}$ for $40 \mathrm{~s}$, extension at $72{ }^{\circ} \mathrm{C}$ for $1 \mathrm{~min}$, and a final elongation at $72{ }^{\circ} \mathrm{C}$ during $5 \mathrm{~min}$. The PCR products were separated by gel electrophoresis at $70 \mathrm{~V}$ for $25 \mathrm{~min}$ on a 3\% (wt/vol) agarose gel in TAE buffer containing Gel Red (1 x final concentration, BIOTIUM) and were visualized under UV light. Two replicate analyses were made for most herbaria samples. A few amplicons from herbaria were sequenced to check that mating genes had been amplified. Since natural infections can be caused by several genotypes of Erysiphe, each sample could theoretically be assigned to MAT1-1, MAT1-2 or MAT1-1 \& MAT12. The mating type ratio of a group of samples was calculated as the number of samples with MAT1-1 (including MAT1-1 \& MAT1-2) to the number of samples with MAT1-2 (including MAT1-1 \& MAT12). This ratio is expected to be close to $1: 1$ in sexually reproducing populations.

Mixed inoculation experiment

In order to investigate interactions between E. alphitoides and E. quercicola, an experiment was set up using inoculations on oak leaves with spore 
suspensions containing different proportions of each species: $\mathrm{A}=100 \%$ E. alphitoides, $\mathrm{B}=75 \%$ E. alphitoides $+25 \%$ E. quercicola, $\mathrm{C}=50 \%$ E. alphitoides $+50 \% \quad$ E. quercicola, $\quad \mathrm{D}=25 \% \quad$ E. alphitoides $+75 \%$ E. quercicola, $\mathrm{E}=100 \%$ E. quercicola. The design was based on the principle of the replacement series, widely used for the study of interference in mixtures of species (Jolliffe 2000), in which the total density of individuals is kept constant. Thus in our case, the same total spore concentration was used for each spore suspension (pure inoculum and mixtures). Since the same total density of spores was inoculated at each point, what is tested through inoculum (pure vs. mixed) and treatment (A-B-C-DE) effects is whether inter- and intra- specific interferences are equal. Three experiments, using different pairs of E. alphitoides / E. quercicola isolates were performed. The Erysiphe isolates had been obtained from naturally infected leaves collected in Cestas (near Bordeaux, France) and multiplied from a single lesion by successive inoculations on oak seedlings to obtain a sufficient number of spores for the experiment. The identity of E. alphitoides and E. quercicola isolates was checked by ITS sequencing.

The different mixtures were obtained as follows. First, concentrated spore suspensions (approx. 100,000 spores $/ \mathrm{mL}$ ) of each species were obtained by harvesting spores from monospore isolate "cultures" maintained on excised oak (Quercus robur) leaves kept in Petri dishes on moist filter paper (since powdery mildew fungi as obligate biotrophs cannot be cultured on axenic media) and adding them in an Eppendorf tube containing sterile water. The concentration of each spore suspension was assessed by counting spores with a hemacytometer. The concentration of the pure suspensions of $E$. alphitoides and $E$. quercicola was then adjusted to 60,000 spores $/ \mathrm{mL}$ by adding sterile water, to obtain $\mathrm{A}$ and $\mathrm{E}$ spore suspensions, respectively. $\mathrm{B}, \mathrm{C}$ and $\mathrm{D}$ suspensions were then obtained by mixing adequate volumes of $\mathrm{A}$ and E. In all these steps, spore suspensions were kept on ice to prevent spore germination or degradation. Inoculations were performed on detached oak leaves on moist filter paper in Petri dishes. Leaves were taken from oak (Quercus robur) seedlings, which had been grown in a greenhouse and were selected at a susceptible stage, with at least five developing leaves on the first flush. A $2.5 \mu \mathrm{L}$ droplet of spore suspension (corresponding to approx. 150 spores) was put on each leaf on the same position (in the middle of the leaf, between lateral veins). Each of the five treatments (A to E) was applied on five leaves of 25 seedlings (i.e. 125 leaves in total). The rank of leaves (from oldest $=1$ to youngest $=5$ ) was recorded so that each treatment was applied to the same number of leaves for a given rank. Inoculated leaves were left in the microbiological hood with high ventilation for one hour with cover lid of Petri dishes open so that water droplets could dry out (since spores cannot germinate in free water). Leaves in closed Petri dishes were then incubated during 10 days in a growth chamber at $22{ }^{\circ} \mathrm{C}$ with a $12 \mathrm{~h}-12 \mathrm{~h}$ photoperiod. At the end of the incubation period, a disc $(1 \mathrm{~cm}$ diameter $)$ was cut off from each leaf, containing the inoculated zone. The quantification of E. alphitoides and E. quercicola spores was carried out by droplet digital PCR (ddPCR), a method providing absolute quantification of specified DNA targets, using a previously developed protocol (Online Resource 1). The ddPCR analyses provided a number of target DNA copies per sample, for E. alphitoides and E. quercicola separately, which was used as a proxy of the number of spores of each species produced at each inoculation point.

Data analyses were performed by using several mixed linear models with different dependent variables (Table 1). In all models, experiment was included as a fixed effect (at least initially, then removed if non-significant) and seedling-nested-inexperiment as a random factor. A leaf rank effect (and interactions with other effects) was included as fixed effect since leaf ontogeny is well known to have a strong effect on powdery mildew susceptibility (Edwards and Ayres 1982). In the first model, we analysed spore production in the different treatments by using the total number of target DNA copies (E. alphitoides $+E$. quercicola) per sample as dependent variable, after log transformation (which normalized residuals). In this first model, we tested both a species effect on spore production (when comparing A and E) and interactive effects between species (i.e. interspecific interaction greater than intra-specific) by comparing pure vs. mixed inoculum and treatment effect. In the second model, the dependent variable was a proxy of "infection efficiency" (or spore yield) per species, calculated for each inoculated leaf as the ratio of the number of specific target DNA copies detected 10 days after inoculation to the theoretical 
Table 1 Statistical models used to investigate competitive effects between E. alphitoides and E. quercicola. In all models, experiment was included as fixed effect and seedling-nested-in experiment as random factor. [xx] indicates levels in a factor; $(\mathrm{xx})$ indicates nested effects

\begin{tabular}{|c|c|c|c|c|}
\hline $\begin{array}{l}\text { Mixed } \\
\text { linear } \\
\text { model }\end{array}$ & Dependent variable & $\begin{array}{l}\text { Biological } \\
\text { significance }\end{array}$ & Observations used in the model & Fixed effects \\
\hline 1 & $\begin{array}{l}\text { Log(number of DNA copies } E \text {. } \\
\text { alphitoides }+ \text { E. quercicola per } \\
\text { sample) }\end{array}$ & $\begin{array}{l}\text { Proxy of total } \\
\text { spore } \\
\text { production per } \\
\text { inoculation } \\
\text { point }\end{array}$ & All & $\begin{array}{l}\text { Inoculum } \\
\text { [pure }=\mathrm{A} \text { and } \mathrm{E} \text { vs. } \\
\text { mixed }=\mathrm{B}-\mathrm{C}-\mathrm{D} \text { ] } \\
\text { Treatment (inoculum) } \\
\text { Leaf rank [ } 1 \text { to } 5] \\
\text { Leaf rank } * \text { Inoculum }\end{array}$ \\
\hline 2 & $\begin{array}{l}\text { Log(number of DNA copies } E \text {. } \\
\text { alphitoides or } E \text {. quercicola per } \\
\text { sample divided by theoretical } \\
\text { number of spores inoculated per } \\
\text { species) }\end{array}$ & $\begin{array}{l}\text { Proxy of } \\
\text { infection } \\
\text { efficiency } \\
\text { (spore yield) } \\
\text { for each species }\end{array}$ & $\begin{array}{l}\text { Treatments A-B-C-D for } E \text {. } \\
\text { alphitoides and B-C-D-E for } E \text {. } \\
\text { quercicola (i.e. non-zero initial } \\
\text { density of spores for E. alphitoides } \\
\text { and E. quercicola) }\end{array}$ & $\begin{array}{l}\text { Species [E. } \\
\text { alphitoides vs. } E \text {. } \\
\text { quercicola] } \\
\text { Inoculum [pure vs. } \\
\text { mixed] } \\
\text { Treatment (inoculum) } \\
\text { Leaf rank [1 to 5] } \\
\text { Species * Leaf rank }\end{array}$ \\
\hline 3 & $\begin{array}{l}\text { Difference between final and initial } \\
\text { frequency } \\
\text { Final = ratio of the number of DNA } \\
\text { copies of each species ( } E \text {. } \\
\text { alphitoides or } E \text {. quercicola) to the } \\
\text { total number of copies }(E \text {. } \\
\text { alphitoides }+ \text { E. quercicola) }\end{array}$ & $\begin{array}{l}\text { Index of } \\
\text { competitiveness }\end{array}$ & $\begin{array}{l}\text { Treatments B-C-D (mixed inoculum) } \\
\text { Analyses performed on E. alphitoides }\end{array}$ & $\begin{array}{l}\text { Leaf rank }[1 \text { to } 5] \\
\text { (no intercept) }\end{array}$ \\
\hline
\end{tabular}

number of spores inoculated for that species (i.e. 150, $112.5,75$ and 37.5 in the treatments corresponding to frequency $=100,75,50$ or 25 in the inoculum mixture, respectively). The variable was not defined in the $\mathrm{E}$ treatment for E. alphitoides and in the $\mathrm{A}$ treatment for E. quercicola. It was log-transformed for analyses. The effects (explaining variables) tested on Spore yield were Species (E. alphitoides vs. E. quercicola), Inoculum (pure vs. mixed), Treatment (Inoculum), Leaf rank and Leaf rank* Species. In the third model, the aim was to compare initial and final frequencies of E. alphitoides and E. quercicola in the mixed inoculations (B, C and D treatments). An index of competitiveness was calculated as the difference between final frequency, calculated as the ratio of target DNA copy number of one species to the total number of DNA copies, and initial frequency for each inoculation point. The analysis was performed on only one species (i.e. E. alphitoides) since proportions of each species are complementary. We tested whether this competitive index (which should be equal to 0 under the null hypothesis of equal inter- and intraspecific interference) varied according to Leaf rank.

Data analysis was implemented with the Proc mixed procedure in SAS software, Version 9.4 (SAS Institute Inc., Cary, NC, USA).

\section{Results}

Identification of Erysiphe species in herbaria specimens

In more than $90 \%$ of samples (191 out of 204), amplified sequences showed strong homology with Erysiphe species. All Erysiphe sequences had $>=$ 99\% homology with the E. alphitoides, E. quercicola or E. hypophylla reference sequences, except for the 
oldest sample collected in 1875. For the latter, collected on Quercus robur by Passerini in Italy, a high similarity with the recently described E. azerbaijanica on Castanea sativa (type specimen, GenBank accession: NR_156336.1) was found (>99\% identity, 1 single SNP out of 156 nucleotides). The second and third oldest samples from 1904 to 1905 from Poland and Czech Republic, respectively, were identified as E. quercicola (showing $100 \%$ sequence similarity). Remarkably, all 27 samples collected between 1900 and 1920 in different European countries were identified as E. quercicola (Figs. 1, 2). Strong changes in the relative frequencies of the three species occurred during the second half of the twentieth century (Fig. 1). E. alphitoides was detected for the first time in a sample collected in 1921 in Austria. From that date until 1960, this species was found occasionally, alone or in mixture with $E$. quercicola in several countries (also in France, Denmark and Switzerland) at an overall frequency never exceeding $25 \%$. A dramatic change occurred in the next decades, after 1960, with E. alphitoides becoming dominant, i.e. found in approx. $75 \%$ of all samples and in almost all countries sampled. E. hypophylla was first detected in a sample collected in 1947 in Switzerland. It was later found also in samples from Finland and Switzerland, but its overall frequency remained low, less than $20 \%$ of all samples.
Presence of chasmothecia and distribution of mating type

Except in the two oldest samples (1875) from Italy, no chasmothecia were observed until 1920 in any of the herbaria specimens, all identified as E. quercicola or undetermined. From that year on, chasmothecia were detected regularly in samples of E. quercicola (Fig. 3, Online Resource 2). Similarly, no chasmothecia were observed in the seven oldest samples of E. alphitoides, from 1923 to 1954, whereas they were detected in 81\% of samples from 1956 onwards. Unlike E. alphitoides and E. quercicola, all ten samples of E. hypophylla had chasmothecia from their first detection in 1947 (Online Resource 2).

The mating type was successfully determined by PCR amplification in 130 out of the 204 samples, but usually for only one replicate. From 1900 to 1920, 21 out of 22 samples of E. quercicola had a positive signal for the MAT1-2 idiomorph. Only one sample in 1912 revealed a mixture between MAT1-2 and MAT1-1. After the year 1920, the frequency of MAT1-1 increased greatly, and the ratio between the two mating types was maintained close to $1: 1$ in successive decades (Fig. 3). A highly significant association was found between presence of chasmothecia and presence of the two mating types in a sample $\left(\mathrm{Chi}^{2}=20.08, d f=1, P<0.0001\right)$. Moreover, the mating type ratio followed a similar temporal trend as

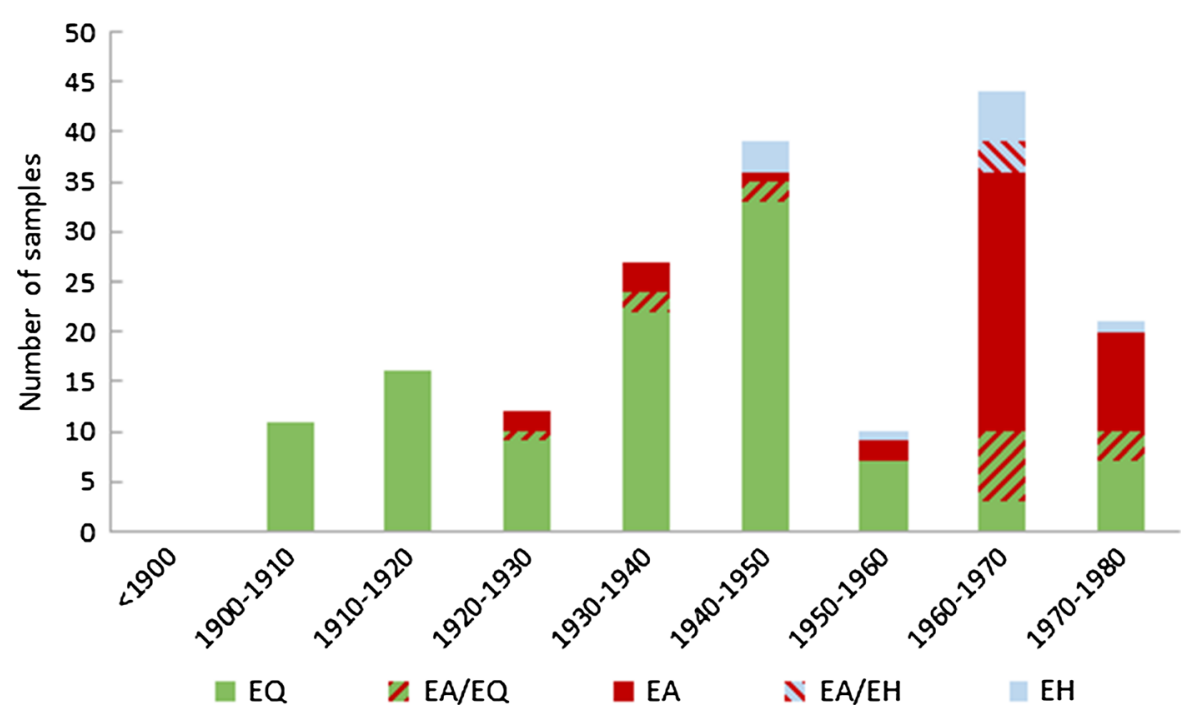

Fig. 1 Temporal changes in the frequency of Erysiphe species $(\mathrm{EA}=$ E. alphitoides; $\mathrm{EQ}=$ E. quercicola $; \mathrm{EH}=$ E. hypophylla $)$, alone or in mixture, detected in oak herbaria samples 

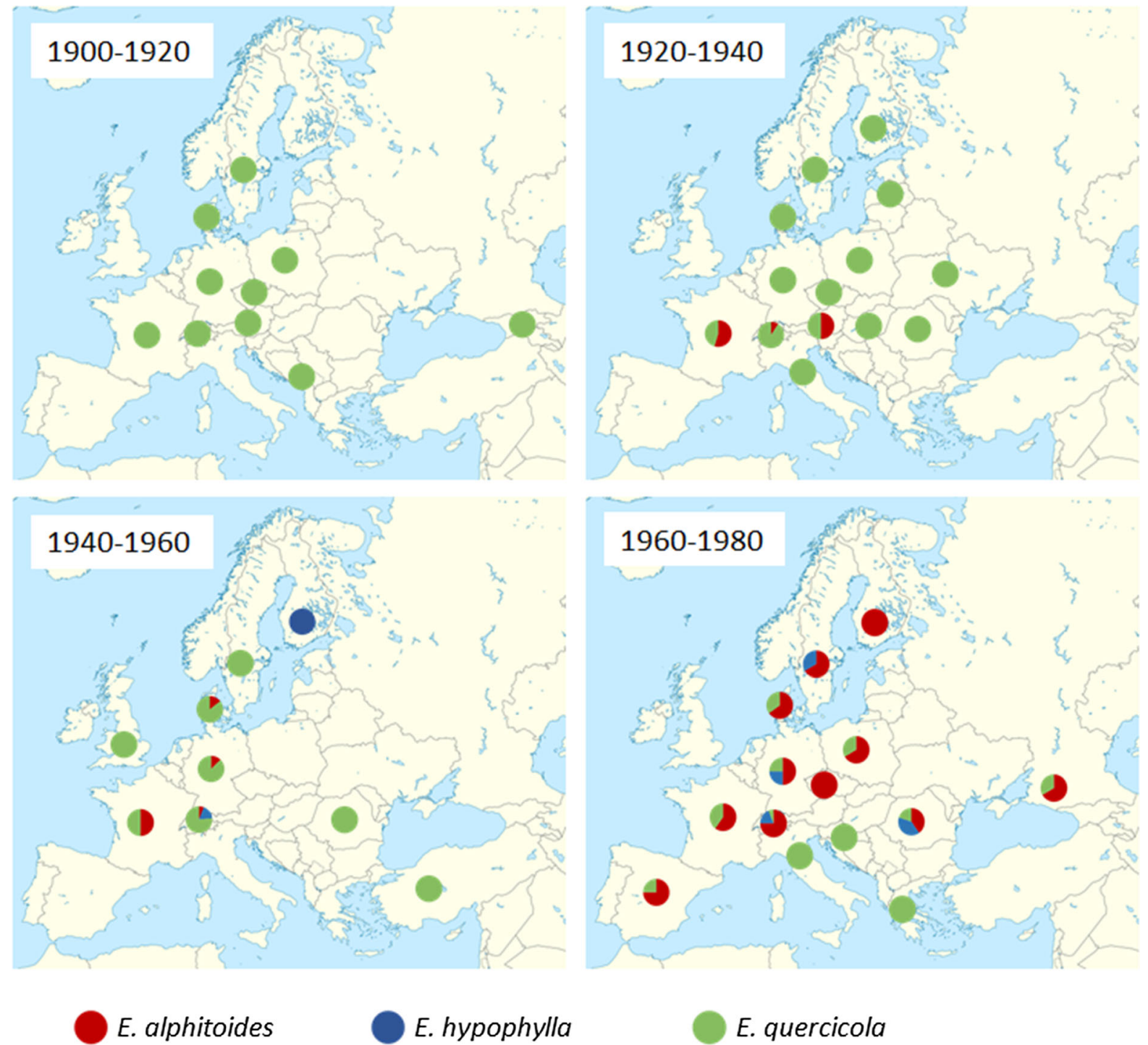

\section{E. quercicola}

Fig. 2 Detection in herbaria samples of the three Erysiphe species associated with oak powdery mildew for different periods across Europe

the frequency of chasmothecia (Fig. 3). The mating type of only one sample of E. alphitoides could be characterized before 1960, as being MAT1-1 \& MAT1-2 (specimen collected in 1940). From 1960 onwards, E. alphitoides was more frequent and both mating type ratios and frequency of chasmothecia were close to 1, e.g. 0.90 (on 19 samples) and 0.96 (on 23 samples), respectively, between 1960 and 1970 . The three E. hypophylla isolates (collected in 1948, 1957, 1961) from which mating type could be characterized were MAT1-1 or MAT1-1 \& MAT1-2.

\section{Co-inoculation experiment}

All detailed statistical analyses can be found in the Online Resource 1.

The E. alphitoides and E. quercicola isolates used in our experiment exhibited similar levels of pathogenicity on average. The total number of DNA copies did not significantly differ between E. alphitoides and E. quercicola when inoculated as pure inoculum, i.e. between $\mathrm{A}$ and $\mathrm{E}$ treatments in the first model $(t=0.36 \mathrm{P}=0.7193)$. Similarly, the infection efficiency, calculated as the ratio of DNA copies 


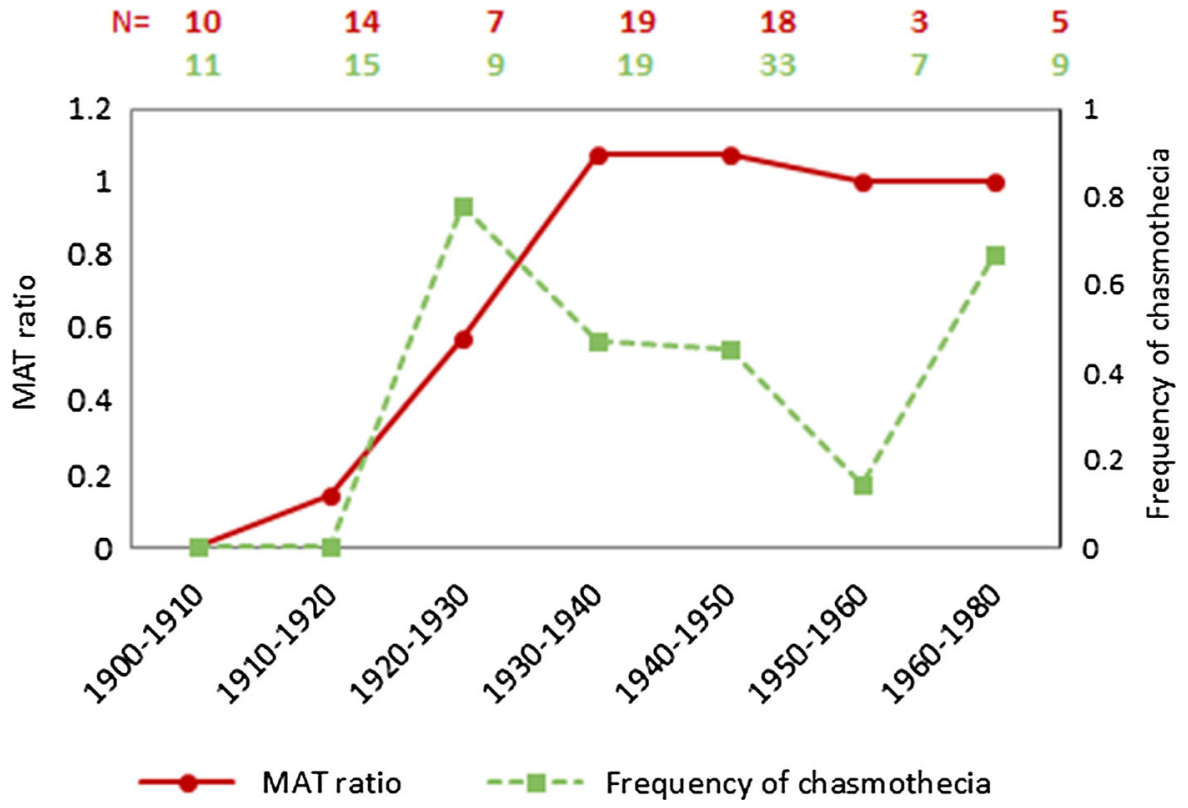

Fig. 3 Relative frequency of mating types (MAT ratio) and of chasmothecia in herbaria samples collected in different decades and identified as Erysiphe quercicola

produced per inoculated spore did not significantly differ overall between E. alphitoides and E. quercicola (no species effect in the second model, F329,1 = 0.71; $P=0.4012$ ).

Differences between pure (one species alone) and mixed inoculations were demonstrated. A tendency of lower spore production (as estimated by target DNA copies detected by ddPCR) in mixed inoculum treatments (i.e. in B, C and D) compared to pure inoculum (Fig. 4) was observed (first model - F172,1 = 3.60;

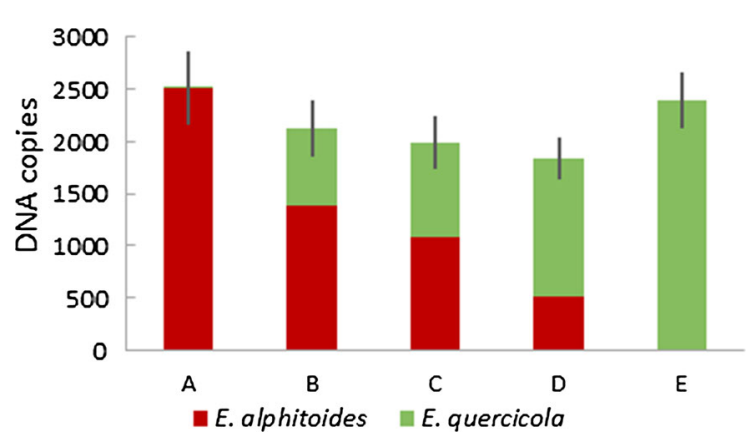

Fig. 4 Number of targeted DNA copies of each species obtained in the different inoculation treatments after 10 days of incubation. The spore density at inoculation was the same in the 5 treatments A to E, with initial relative proportions of $E$. alphitoides/ E. quercicola $=100 / 0 ; 75 / 25 ; 50 / 50 ; 25 / 75$ and $100 / 0$, respectively. The interval above bars indicates the standard error of the mean of total copies
$P=0.0595)$. Furthermore, for both species, infection efficiency was greater in pure inoculations than in inoculations in mixture with the other species (Second model-Inoculum F $329,1=23.03 ; \quad P<0.0001$ ) (Fig. 5).

Importantly, leaf rank was shown to strongly affect infection by each species and their interaction. The infection efficiency was highest on the youngest leaf for both species but a stronger decrease was observed

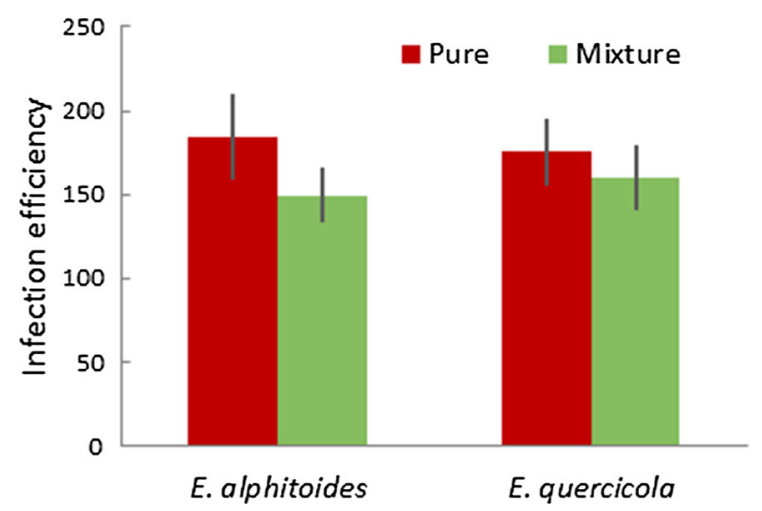

Fig. 5 Mean infection efficiency (estimated as the ratio of targeted DNA copies detected 10 days after inoculation to the estimated number of spores used for inoculation) for $E$. alphitoides and E. quercicola when inoculated alone or in mixture with the other species 
on older leaves for E. quercicola than for $E$. alphitoides, resulting in only $24 \%$ of maximal infection efficiency on leaf 1 for E. quercicola (as compared to leaf 5) as compared to $53 \%$ for $E$. alphitoides (Fig. 6; significant Leaf rank effect $\mathrm{F}_{329,4}=2.59 ; P=0.0369$ and Leaf rank*Species interaction $\mathrm{F}_{329,4}=6.88 ; P<0.0001$ in the second model). This resulted in a greater infection efficiency for $E$. alphitoides than for E. quercicola on oldest leaves ( $\mathrm{t}=3.21, P=0.0015)$. In agreement, the difference between final and initial frequencies for each species (third model) varied according to leaf rank $\left(\mathrm{F}_{86,4}=\right.$ $4.54 ; P=0.0022$; Fig. 7). On the oldest leaves (F1 and F2), E. alphitoides was detected at higher frequencies 10 days after inoculation than in the initial inoculum, corresponding to a significantly positive competitive index $\left(\mathrm{t}{ }_{86}=3.11 P=0.0025\right.$ for $\mathrm{F} 1 ; \mathrm{t}{ }_{86}=2.24$ $P=0.0275$ for $\mathrm{F} 2$; 0 value of competitive index not included in the confidence interval - $t$ values were nonsignificant for other leaves).

\section{Discussion}

Our study based on analyses of herbaria specimens provided several unexpected findings that challenge the currently admitted scenario of oak powdery mildew invasion in Europe based on historical reports (Mougou et al. 2008). The new scenario, strongly supported by evidence, resolve apparent contradictions (detailed below) in the history of this invasion by a complex of closely related species. Our results suggest that the first invasive species experienced

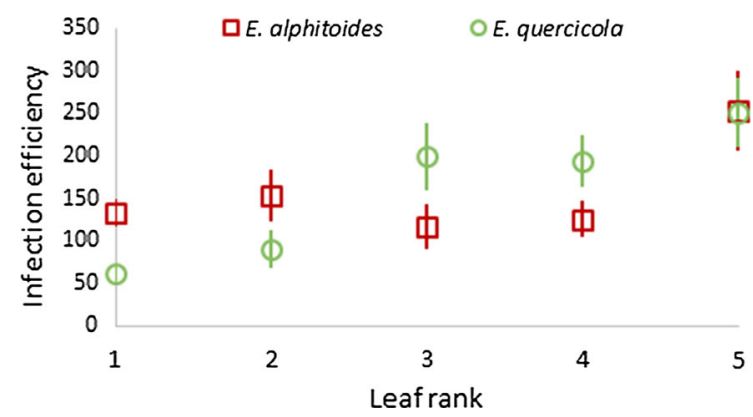

Fig. 6 Mean infection efficiency (estimated as the ratio of targeted DNA copies detected 10 days after inoculation to the estimated number of spores used for inoculation) for $E$. alphitoides and E. quercicola on developing leaves of different ages $($ from oldest $=1$, to youngest $=5$ )

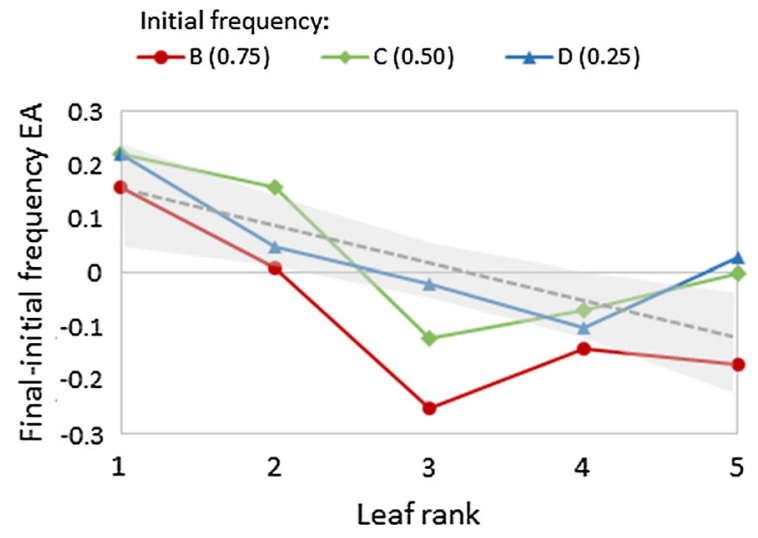

Fig. 7 Variation in E. alphitoides competitive index (estimated as the difference between its final- and initial frequency in inoculated leaves) according to leaf rank (from oldest $=1$ to youngest $=5$ ). The dotted line and confidence interval at $95 \%$ correspond to the linear regression of the index (final- initial frequency) on leaf rank used as a quantitative variable

niche contraction after over-invasion of the second species and point to several mechanisms potentially explaining this outcome. Our case study thus improves our understanding of multiple invasions by closely related, functionally equivalent species (Russell et al. 2014), which is of particular significance for fungi.

Evidence of a silent epidemic (lag phase)

before records of disease emergence

The first striking finding of our study is that, with the help of herbaria specimens, it was possible to date the presence of oak powdery mildew to as early as the year 1904 (excluding the two oldest specimens corresponding to another taxon), i.e. three years earlier than the first report of symptoms in the literature (Hariot 1907). It should be pointed out here that all the time estimates based on herbaria samples have to be taken with caution since they were gained by a limited sampling of herbaria specimens. An even earlier introduction is thus likely. Our finding helps to explain the fact that the species was detected in many European countries (England, Germany, Austria, Belgium, Portugal, Italy, Scandinavia, Switzerland) in 1908, only a single year after the first mentioning in the literature. Obviously, the epidemic had started before but was only noticed by few mycologists and was not reported in the literature. Lags in detection (i.e. time between entry and discovery of an invasive species) are very common in undeliberate introductions since 
populations often grow exponentially in the early phases of invasion and they become noticed only when they reach high density or cause significant damage (Crooks 2005). Such a lag was already reported for some fungal pathogens, e.g. H. fraxineus (Gross et al. 2014).

The history of powdery mildew in Europe revisited

The second striking result of our study is the detection of E. quercicola and not E. alphitoides in herbaria samples from 1900 to 1920 , and predominantly until the 1960's. This strongly suggests that E. quercicola arrived before E. alphitoides and caused the emergence of oak powdery mildew in Europe in the beginning of the twentieth century. One of our analysed sample was collected in 1908 by Hariot who made the first disease report (Hariot 1907). However, E. alphitoides was described in 1912 as the new species associated with the disease (Griffon and Maublanc 1912; Mougou et al. 2008). This apparent contradiction can be explained by the fact that the current E. alphitoides description is not based on the holotype (= original sample from which the species description was based initially) but on a neotype, consisting of a Swiss sample of oak powdery mildew collected in 1999. At the time of this neo-typification, the holotype of E. alphitoides had been lost and $E$. quercicola was only known from Japan (Takamatsu et al. 2007). When looking at descriptions and drawings of chasmothecia included in the early reports of oak powdery mildew in Europe (e.g. Arnaud and Foex 1912; Griffon and Maublanc 1912), they are indeed more suggestive of E. quercicola than of $E$. alphitoides, if looking at the relative length of appendages and diameter of chasmothecia which are considered as a differential feature between the two species (Takamatsu et al. 2007; Online Resource 1). Although the morphology of the anamorphic (asexual) stage of the two species has generally been considered as similar, a difference in conidia morphology was found in this study (Online Resource 1). Our findings supporting E. quercicola as the causal agent of the emergence of powdery mildew are also consistent with early observations on the pathogen cycle. From 1907 to 1911, the new oak powdery mildew was reported as overwintering in the anamorphic stage, as mycelium or conidia in buds, leading to a typical symptom at budburst called flagshoots, i.e. strongly infected shoots with young developing leaves covered with conidia. However, this symptom has always been associated with E. quercicola and never with $E$. alphitoides in recent samples (Feau et al. 2012).

Evidence of a (cryptic) over-invasion leading to spatial and temporal niche contraction of the first introduced species.

The detection of E. quercicola in herbaria samples all over Europe, including Nordic countries, from 1900 to 1960, was another unexpected finding of our study since it is now known almost exclusively from southern Europe (Desprez-Loustau et al. 2018). The strong increase in E. alphitoides frequency in herbaria samples from its first detection in 1920 leading to its predominance after the 1950's (and still nowadays, Desprez-Loustau et al. 2018) strongly suggests that $E$. alphitoides was the cause of the partial displacement of E. quercicola. E. alphitoides may have been introduced a few years after E. quercicola, grew exponentially and spread. Alternatively, the two species may have been introduced together, but in conditions giving E. quercicola a strong initial advantage. Some authors suggested that oak powdery mildew first appeared in Portugal at the end of the nineteenth century and that it was introduced (possibly much earlier) not on contaminated oaks but on other hosts, such as tropical plants (Torrend 1909, Online Resource 1). Interestingly, molecular phylogenetic analyses and cross inoculations suggest close relationships (even conspecificty) between powdery mildew fungi on tropical plants, especially mango, and on oaks (Boesewinckel 1980; Desprez-Loustau et al. 2017, Limkaisang et al. 2006, Ajitomi et al. 2020). Both E. alphitoides and E. quercicola have been found on mango trees and other tropical plants, but most frequently E. quercicola (Desprez-Loustau et al. 2017; Nasir et al. 2014). One can therefore hypothesize an introduction of both $E$. alphitoides and E. quercicola on common hosts, but with E. quercicola at higher densities than E. alphitoides, maybe also due to its ability to survive in buds. Moreover, if this introduction took place in southern Europe, E. quercicola may have found both climatic conditions, e.g. warmer temperatures in winter, and hosts, e.g. Pyrenean oak $(Q$. pyrenaica $=Q$. toza $)$, favouring its development (Takamatsu et al. 2007; Desprez-Loustau et al. 2018). Unfortunately, we could not obtain 
herbaria specimens from Portugal and Spain supporting this early history. With E. alphitoides overinvasion, especially after the 1960's, E. quercicola would have been progressively restricted to southern Europe. As a general rule, niche contraction of a species as a result of exposure to a threat is expected to restrict the niche to areas where the threat impact is reduced, often in relation to environmental heterogeneity, and thus to areas where the competitive ability of the species is maintained (Scheele et al. 2017). Similarly, niche shift or ecological character displacement, has been described as a process facilitating coexistence in recently encountered species with initial similar niche, through niche partitioning (Stroud et al. 2019).

Herbaria analyses also suggest that niche contraction of E. quercicola had a temporal dimension. Most herbaria specimens were collected at the end of summer or autumn (August to November), probably because mycologists were looking at fruiting bodies (chasmothecia) which are the main structures for diagnostic purposes (but see Online Resource 1 about differences in the morphology of conidia). This suggests that, in the beginning of the twentieth century, E. quercicola was able to develop and cause symptoms all along the season. Although herbaria specimens cannot be considered a systematic sampling, there seems to be a contrast with the recent period since several studies showed that E. quercicola is mostly associated with spring symptoms (on the first flush) and can hardly be found at the end of the season (Feau et al. 2012; Hamelin et al. 2016). Temporal niche contraction has been far less documented than spatial niche contraction (Scheele et al. 2017) but some examples can be found (Ishii and Higashi 2001).

Leaf ontogeny and ontogenic resistance

as a crucial factor in species interference

How can the spatial and temporal niche reduction of $E$. quercicola, leading to its partial displacement as a result of the over-invasion of E. alphitoides, be explained? Although several mechanisms may be involved in species displacement after invasion of another species, competition between two newly interacting species is often considered as a key component (Gurevitch and Padilla 2004; Gao and Reitz 2017). But assessing the fitness advantage of a species over another one is challenging since the whole interacting space of two species is not easily tractable. Our experimental approach with E. alphitoides and E. quercicola is limited to interaction effects during leaf infection after inoculations with high spore loads to maximize potential interference effects. Our results suggest some level of negative interaction between the two species, as shown by decreased infection efficiency of each species in mixed inoculum with the other species. Direct antagonism cannot be discarded in absence of more detailed investigations. However, a more likely explanation would be an effect of competition, including both socalled interference and exploitative competition, i.e. competition for space and resources (Boddy 2000). Most interestingly, this competition effect was strongly affected by leaf phenology. The very young leaves appeared as the most favourable for sporulation of the two fungal species, in agreement with previous experiments showing ontogenetic resistance of mature oak leaves to powdery mildew (Edwards and Ayres 1982). However, leaf aging had a strikingly different effect on E. alphitoides and E. quercicola. Whereas susceptibility to E. quercicola strongly decreased during leaf development, E. alphitoides appeared more plastic, i.e. its sporulation was much less reduced on older leaves. A significant competitive advantage of E. alphitoides could be detected on these older leaves. This small experimental difference may have a great significance in nature by providing $E$. alphitoides a much wider susceptibility window during the whole growing season. The importance of temporal aspects or phenology in the interaction between closely related species and their coexistence or displacement has already been emphasized (Hamelin et al. 2016; Gao and Reitz 2017). The difference between E. alphitoides and E. quercicola in their ability to infect older leaves, and not only very young leaves of currently growing shoots, may have had crucial implications in terms of reproductive strategy. Indeed, sexual reproduction in powdery mildew fungi, leading to the formation of chasmothecia, occurs at the end of the season, on senescing leaves. The observation of the sexual morph (chasmothecia) in herbaria specimens identified as E. quercicola between 1920 and 1980 strongly suggest that they belonged to E. quercicola, as also supported by a few sequences obtained from DNA tentatively extracted from fruiting bodies isolated from surrounding mycelium (data not shown). The absence of chasmothecia in the early invasion 
phase could be simply explained by the absence or very low frequency of one mating type, due for example, to a first clonal expansion in Europe of few genotypes mostly bearing the Mat-1-2. This explanation was suggested by early observers (Behrens 1921) and the absence of sexual fruiting bodies in the first years following introduction has been documented in several other cases with heterothallic fungi (Paoletti et al. 2006; Boron et al. 2016), including grapevine powdery mildew (Yarwood 1957). Chasmothecia associated with $E$. quercicola infection were increasingly observed while disequilibrium in mating type ratio decreased in the subsequent decades. However, the presence of E. quercicola chasmothecia in herbaria specimens was mainly observed in a period when $E$. alphitoides was at low frequency and they are almost never observed in contemporary samples (Mougou et al. 2008; Marçais et al. 2009; Feau et al. 2012). It may be hypothesized that when E. alphitoides spread in Europe, its better ability to infect older leaves compared to E. quercicola led to its much higher frequency on leaves in autumn. This could have favoured in turn a greater sexual reproductive success, which possibly contributed to its invasive success (Philibert et al. 2011; Bazin et al. 2014). Therefore, our findings could be interpreted as a form of reproductive (sexual) interference, where the competitive advantage of E. alphitoides on older leaves "constrained" E. quercicola to development on youngest leaves, only in the asexual stage, while E. alphitoides had the free space for sexual reproduction in autumn. Reproductive interference has been involved in animal or plant species displacements (Gao and Reitz 2017; Nishida et al. 2017), but never in fungi to our knowledge.

Reproductive interference between $E$. alphitoides and E. quercicola could explain the geographic niche reduction of E. quercicola. Indeed, sexual fruiting bodies in powdery mildew fungi are also resistance forms for overwintering. In their absence, overwintering in the asexual form in buds is limited in very cold winters (Marcais et al. 2017). The ability of $E$. quercicola to infect leaf primordia and survive winter in buds, giving it a priority effect in spring, is therefore limited to warmer areas which can explain the contemporary distribution of E. quercicola restricted to southern Europe, in the optimal part of the historical distribution (Scheele et al. 2017).

\section{Conclusions}

Our results provide new insights into the history of the oak powdery mildew invasion in Europe. They strongly suggest that E. quercicola was the first invading powdery mildew species on oaks in Europe in the early twentieth century, although another Erysiphe species was detected on oaks in 1875 in Italy, and that E. alphitoides over-invaded in a second stage. Interestingly, another multiple invasion involving a complex of Erysiphe species associated with oak powdery mildew, but with E. alphitoides overtaken by an American species, was reported to have occurred in South Africa in the middle of the twentieth century (Gorter 1984). This other multiple invasion would deserve further investigation since molecular species identifications were not available at that time and have not been used ever since. As concerns Europe, our results showed that E. quercicola was not totally displaced by $E$. alphitoides but experienced severe niche contraction, in several of its temporal (season) and spatial (age of leaves, geographic range) dimensions, as well as being affected in its reproduction. Our findings related to the outcome of the successive invasions of E. quercicola and E. alphitoides are fitting well a theoretical model suggesting that the coexistence of the two species could be mediated by a trade-off between within-season transmission, in favour of E. alphitoides, and between-season transmission, in favour of E. quercicola only in nonlimiting winter conditions (Hamelin et al. 2016; Desprez-Loustau et al. 2019).

Beyond the reconstruction of the history of an important forest disease, our investigation illustrates the complexity of a multiple invasion in a microbial complex, emphasizing the potential role of subtle differences in the biology of closely related species, rather than strong direct competition, in the observed pattern of partial species displacement. Many other components not explored here may be involved, such as interactions with natural enemies (Xing et al. 2017; Kiss 2008) or human interference (Gao and Reitz 2017). For this later point, it is interesting to note that silvicultural practices in oak forests greatly changed in the twentieth century, partly in response to powdery mildew invasion (Viney 1970), favouring high forest at the expense of coppices that were most frequent before. This could have also favoured the predominance of E. alphitoides, less dependent than $E$. 
quercicola on new succulent shoots (Desprez- Loustau et al. 2018). Improved understanding of multiple invasions, especially for microbes that often come unnoticed, is crucial owing to their increased frequency and negative impacts. Microbial pathogens often occur as species complexes in their natural area (Rouxel et al. 2013; Gross and Han 2015; Zheng and Zhuang 2013), constituting reservoirs of potential multiple species introductions. Keeping in mind the possibility of an over-invasion by a related pathogenic species for a given disease caused by an introduced pathogen may have important implications for policy and management (Landolt et al. 2016). Even if overinvasion does not necessarily involve increased aggressiveness (Mariette et al. 2016), new risks may emerge, through hybridization between introduced species for example, as already demonstrated for Dutch Elm Disease and Alder Phytophthora decline (Brasier and Buck 2001; Ioos et al. 2006).

Finally, we would like to emphasize the importance of biological collections to preserve current and past biological samples, which is the only way to keep tracks of changes and provide full understanding of emerging epidemics. Interestingly the history of the iconic potato late blight was also revisited by using herbaria specimens which showed that the lineage previously thought to be responsible of the Great Irish Famine was actually a secondary invader which replaced the original lineage (Yoshida et al. 2014). It would be interesting to further investigate whether interactions between lineages of the same species or of closely related species involve some common mechanisms (Gladieux et al. 2015).

Acknowledgements We would like to thank the herbaria staff and curators D. Triebel (Bot. Staatssammlungen Munich, Germany), C. Lange (Natural history museum of Denmark), A. D. Bond (Royal Botanical gardens fungarium, United Kingdom), R. Berndt (Fungarium Z Z ZT, Zurich, Switzerland), V. Queloz and V. Dubach (forest protection service herbarium, WSL, Switzerland), Paul Seimandi and Nathalie Delmas (Université Paul Sabatier, Tourlouse), Philippe Richard and Dominique Vivent (Jardin Botanique, Bordeaux). Furthermore, Iben Margrete Thomsen is thanked for the hint to contact the natural history museum of Denmark for samples. Andrin Gross benefitted from an IdEx-Université de Bordeaux and Agreenskills post-doctoral fellowship grant.

Authors' contributions AG and MLDL designed the study of herbaria specimens; MLDL designed the competition experiment. $\mathrm{AG}$ and $\mathrm{CP}$ performed molecular analyses on herbaria specimens. AG, CD, BL, JFA and LD developed the
MAT protocol and performed the analyses. MM developed the ddPCR protocol and performed analyses with JFA. MLDL and GSJ performed the competition experiment. MLDL carried out statistical analyses. MLDL and AG drafted the first version of the manuscript, with inputs from CD and MM. All co-authors revised the manuscript and approved the version submitted to publication.

Funding Open Access funding provided by Lib4RI - Library for the Research Institutes within the ETH Domain: Eawag, Empa, PSI \& WSL. Andrin Gross benefitted from an IdExUniversité de Bordeaux and Agreenskills post-doctoral fellowship grant.

Availability of data and materials Most data are given in supplementary material. Sequences of genotyped herbaria specimens as well as partial mating type gene sequences were submitted to ncbi Genbank and accession numbers are provided. Any further information can be obtained from request to the authors.

Code availability The scripts for statistical analyses are given in supplementary material.

\section{Compliance with ethical standards}

Conflict of interest The authors declare that they have no conflicts of interest.

Ethics approval Not relevant.

Consent to participate The authors declare that they gave their consent to participate in the investigation.

Consent for publication The authors declare that they consent to the publication.

Open Access This article is licensed under a Creative Commons Attribution 4.0 International License, which permits use, sharing, adaptation, distribution and reproduction in any medium or format, as long as you give appropriate credit to the original author(s) and the source, provide a link to the Creative Commons licence, and indicate if changes were made. The images or other third party material in this article are included in the article's Creative Commons licence, unless indicated otherwise in a credit line to the material. If material is not included in the article's Creative Commons licence and your intended use is not permitted by statutory regulation or exceeds the permitted use, you will need to obtain permission directly from the copyright holder. To view a copy of this licence, visit http://creativecommons.org/licenses/by/4.0/.

\section{References}

Ajitomi A, Takushi T, Sato Y, Arasaki C, Ooshiro A (2020) First report of powdery mildew of mango caused by Erysiphe quercicola in Japan. J Gen Plant Pathol 86:316-321 
Arnaud G, Foex E (1912) Sur la forme parfaite de l'Ö̈dium du chêne. C R Acad Sci 154:124

Bazin E, Mathé-Hubert H, Facon B, Carlier J, Ravigné V (2014) The effect of mating system on invasiveness: some genetic load may be advantageous when invading new environments. Biol Invasions 16:875-886

Behrens J (1921) Die Perithecien des Eiehenmeltaues in Deutschland. Z Pflanzenkrankh XXXI:108-110

Blackburn TM, Ewen JG (2017) Parasites as drivers and passengers of human-mediated biological invasions. EcoHealth 14:61-73

Blackwell M (2011) The fungi: 1, 2, 3. 5.1 million species? Am J Bot 98:426-438

Boddy L (2000) Interspecific combative interactions between wood-decaying basidiomycetes. FEMS Microbiol Ecol 31:185-194

Boesewinkel HJ (1980) The identity of mango mildew, Oidium mangiferae. Phytopathol Z 99:126-130

Boroń P, Lenart-Boroń A, Mullett M (2016) The distribution of Dothistroma septosporum and its mating types in Poland. Forest Pathol 46:489-496

Brasier CM, Buck KW (2001) Rapid evolutionary changes in a globally invading fungal pathogen (Dutch elm disease). Biol Invasions 3:223-233

Brewer MT, Cadle-Davidson L, Cortesi P, Spanu PD, Milgroom MG (2011) Identification and structure of the mating-type locus and development of PCR-based markers for mating type in powdery mildew fungi. Fungal Genet Biol 48:704-713

Crooks JA (2005) Lag times and exotic species: The ecology and management of biological invasions in slow-motion 1 . Ecoscience 12:316-329

Crous PW, Groenewald JZ, Slippers B, Wingfield MJ (2016) Global food and fibre security threatened by current inefficiencies in fungal identification. Philos Trans $\mathrm{R}$ Soc London Ser B 371:20160024

DeBach P (1966) The competitive displacement and coexistence principles. Annu Rev Entomol 11:183-212

Desprez-Loustau ML, Feau N, Mougou-Hamdane A, Dutech C (2011) Interspecific and intraspecific diversity in oak powdery mildews in Europe: coevolution history and adaptation to their hosts. Mycoscience 52:165-173

Desprez-Loustau ML, Hamelin F, Marçais B (2019) The ecological and evolutionary trajectory of oak powdery mildew in Europe. In: Wilson K, Fenton A, Tompkins D (eds) Wildlife disease ecology: linking theory to data and application. Cambridge University Press, Cambridge, pp 429-457

Desprez-Loustau ML, Robin C, Buee M, Courtecuisse R, Garbaye J, Suffert F et al (2007) The fungal dimension of biological invasions. Trends Ecol Evol 22:472-480

Desprez-Loustau ML, Massot M, Feau N, Fort T, de Vicente A, Torés JA, Ortuño DF (2017) Further support of conspecificity of oak and mango powdery mildew and first report of Erysiphe quercicola and Erysiphe alphitoides on mango in mainland Europe. Plant dis 101:1086-1093

Desprez-Loustau ML, Massot M, Toïgo M, Fort T et al. (2018) From leaf to continent: the multi-scale distribution of an invasive cryptic pathogen complex on oak. Fungal Ecol 36:39-50
Dunn AM, Hatcher MJ (2015) Parasites and biological invasions: parallels, interactions, and control. Trends Parasitol 31:189-199

Dutech C, Feau N, Lesur I, Ehrenmann F, Letellier T, Li B, Mouden C, Guichoux E, Desprez-Loustau M-L, Gross A (2020) An easy and robust method for isolation and validation of single nucleotide polymorphic markers from a first Erysiphe alphitoides draft genome. Mycol Prog 19:615-628

Dvorak M, Rotkova G, Botella L (2015) Detection of airborne inoculum of Hymenoscyphus fraxineus and H. albidus during seasonal fluctuations associated with absence of apothecia. Forests 7:1

Edwards MC, Ayres PG (1982) Seasonal changes in resistance of Quercus petraea (sessile oak) leaves to Microsphaera alphitoides. Trans Br Mycol Soc 78:569-571

Enderle R, Stenlid J, Vasaitis R (2019) An overview of ash (Fraxinus spp.) and the ash dieback disease in Europe. CAB Rev 14:1-12

Feau N, Lauron-Moreau A, Piou D, Marçais B, Dutech C, Desprez-Loustau ML (2012) Niche partitioning of the genetic lineages of the oak powdery mildew complex. Fungal Ecol 5:154-162

Fisher MC, Garner TW, Walker SF (2009) Global emergence of Batrachochytrium dendrobatidis and amphibian chytridiomycosis in space, time, and host. Annu Rev Microbiol 63:291-310

Fisher MC, Henk DA, Briggs CJ, Brownstein JS, Madoff LC, McCraw SL, Gurr SJ (2012) Emerging fungal threats to animal, plant and ecosystem health. Nature 484:186-194

Fitt BD, Huang YJ, van den Bosch F, West JS (2006) Coexistence of related pathogen species on arable crops in space and time. Annu Rev Phytopathol 44:163-182

Gao Y, Reitz SR (2017) Emerging themes in our understanding of species displacements. Annu Rev Entomol 62:165-183

Gladieux P, Feurtey A, Hood ME, Snirc A, Clavel J, Dutech C et al (2015) The population biology of fungal invasions. Mol Ecol 24:1969-1986

Gorter GJMA (1984) The identity of the oak powdery mildew in South Africa. S Afr For J 129:81-82

Griffon E, Maublanc A (1912) Les Microsphaera des Chênes. Bull Soc Mycol F 28:88-104

Gross A, Han JG (2015) Hymenoscyphus fraxineus and two new Hymenoscyphus species identified in Korea. Mycol Prog 14:1-13

Gross A, Holdenreider O, Pautasso M, Queloz V, Sieber TN (2014) Hymenoscyphus pseudoalbidus, the causal agent of European ash dieback. Mol Plant Pathol 15:109-117

Gurevitch J, Padilla DK (2004) Are invasive species a major cause of extinctions? Trends Ecol Evol 19:470-474

Hamelin FM, Bisson A, Desprez-Loustau ML, Fabre F, Mailleret L (2016) Temporal niche differentiation of parasites sharing the same plant host: oak powdery mildew as a case study. Ecosphere 7:e01517

Hariot P (1907) Note sur un oïdium du chêne. Bull Soc Mycol F 23:157-159

Hatcher MJ, Dick JT, Dunn AM (2012) Disease emergence and invasions. Funct Ecol 26:1275-1287

Hawksworth DL, Lücking R (2017) Fungal diversity revisited: 2.2 to 3.8 million species. The fungal kingdom, pp 79-95 
Ioos R, Andrieux A, Marçais B, Frey P (2006) Genetic characterization of the natural hybrid species Phytophthora alni as inferred from nuclear and mitochondrial DNA analyses. Fungal Gen Biol 43:511-529

Ishii R, Higashi M (2001) Coexistence induced by pollen limitation in flowering-plant species. Proc R Soc Lond Ser B 268:579-585

Jolliffe PA (2000) The replacement series. J Ecol 88:371-385

Kiss L (2008) Intracellular mycoparasites in action: interactions between powdery mildew fungi and Ampelomyces. In: Avery S, Stratford M, Van West P (eds) Stress in yeast and filamentous fungi. Elsevier Academic Press, Cambridge, MA, USA, pp 37-52

Koukol O, Hanackova Z, Dvorak M, Havrdova L (2015) Unseen, but still present in Czechia: Hymenoscyphus albidus detected by real-time PCR, but not by intensive sampling. Mycol Prog 15:6

Landolt J, Gross A, Holdenreider O, Pautasso M (2016) Ash dieback due to Hymenoscyphus fraxineus: what can be learnt from evolutionary ecology? Plant Pathol 65:1056-1070

Limkaisang S, Cunnington JH, Wui LK, Salleh B, Sato Y, Divarangkoon R et al (2006) Molecular phylogenetic analyses reveal a close relationship between powdery mildew fungi on some tropical trees and Erysiphe alphitoides, an oak powdery mildew. Mycoscience 47:327-335

Linzmaier SM, Goebel LS, Ruland F, Jeschke JM (2018) Behavioral differences in an over-invasion scenario: marbled vs. spiny-cheek crayfish Ecosphere 9:e02385

MacDougall AS, Gilbert B, Levine JM (2009) Plant invasions and the niche. J Ecol 97:609-615

Mallon CA, Van Elsas JD, Salles JF (2015) Microbial invasions: the process, patterns, and mechanisms. Trends microbiol 23:719-729

Marçais B, Kavkova M, Desprez-Loustau ML (2009) Phenotypic variation in the phenology of ascospore production between European populations of oak powdery mildew. Ann For Sci 66:814

Marçais B, Piou D, Dezette D, Desprez-Loustau ML (2017) Can oak powdery mildew severity be explained by indirect effects of climate on the composition of the Erysiphe pathogenic complex? Phytopathology 107:570-579

Mariette N, Mabon R, Corbière R, Boulard F, Glais I, Marquer B et al (2016) Phenotypic and genotypic changes in French populations of Phytophthora infestans: are invasive clones the most aggressive? Plant Pathol 65:577-586

McKinney LV, Thomsen IM, Kjaer ED, Bengtsson SBK, Nielsen LR (2012) Rapid invasion by an aggressive pathogenic fungus (Hymenoscyphus pseudoalbidus) replaces a native decomposer (Hymenoscyphus albidus): a case of local cryptic extinction? Fungal Ecol 5::663-669

Mougou A, Dutech C, Desprez-Loustau ML (2008) New insights into the identity and origin of the causal agent of oak powdery mildew in Europe. For Pathol 38:275-287

Mougou-Hamdane A, Giresse X, Dutech C, Desprez-Loustau ML (2010) Spatial distribution of lineages of oak powdery mildew fungi in France, using quick molecular detection methods. Ann For Sci 67:212-212

Nasir M, Mughal SM, Mukhtar T, Awan MZ (2014) Powdery mildew of mango: a review of ecology, biology, epidemiology and management. Crop Prot 64:19-26
Nishida S, Hashimoto K, Kanaoka MM, Takakura KI, Nishida T (2017) Variation in the strength of reproductive interference from an alien congener to a native species in Taraxacum. J Plant Res 130:125-134

Paoletti M, Buck KW, Brasier CM (2006) Selective acquisition of novel mating type and vegetative incompatibility genes via interspecies gene transfer in the globally invading eukaryote Ophiostoma novo-ulmi. Mol Ecol 15:249-262

Philibert A, Desprez-Loustau ML, Fabre B, Frey P, Halkett F, Husson $C$ et al (2011) Predicting invasion success of forest pathogenic fungi from species traits. J Appl Ecol 48:1381-1390

Rauschert ESJ, Shea K (2012) Invasional interference due to similar inter-and intraspecific competition between invaders may affect management. Ecol Appl 22:1413-1420

Reitz SR, Trumble JT (2002) Competitive displacement among insects and arachnids. Annu Rev Entomol 47:435-465

Ricciardi A, Blackburn TM, Carlton JT, Dick JT, Hulme PE, Iacarella JC et al (2017) Invasion science: a horizon scan of emerging challenges and opportunities. Trends Ecol Evol 32:464-474

Rouxel M, Mestre P, Comont G, Lehman BL, Schilder A, Delmotte F (2013) Phylogenetic and experimental evidence for host-specialized cryptic species in a biotrophic oomycete. New Phytol 197:251-263

Russell JC, Sataruddin NS, Heard AD (2014) Over-invasion by functionally equivalent invasive species. Ecology 95:2268-2276

Scheele BC, Foster CN, Banks SC, Lindenmayer DB (2017) Niche contractions in declining species: mechanisms and consequences. Trends Ecol Evol 32:346-355

Schröder S, Telle S, Nick P, Thines M (2011) Cryptic diversity of Plasmopara viticola (Oomycota, Peronosporaceae) in North America. Org Divers Evol 11:3-7

Stroud JT, Giery ST, Outerbridge M, Feeley KJ (2019) Ecological character displacement alters the outcome of priority effects during community assembly. Ecology 100:e02727

Takamatsu S, Braun U, Limkaisang S, Kom-Un S, Sato Y, Cunnington JH (2007) Phylogeny and taxonomy of the oak powdery mildew Erysiphe alphitoides sensu lato. Mycol Res 111:809-826

Taylor JW, Jacobson DJ, Kroken S, Kasuga T, Geiser DM, Hibbett DS, Fisher MC (2000) Phylogenetic species recognition and species concepts in fungi. Fungal Genet Biol 31:21-32

Torrend C (1909) L'Oidium du Chene en Portugal et a l'ile de Madere. Rev Sci Natur Collegio S Fiel Ser Bot VIII, Brotéria, pp 103-113

Untergasser A, Cutcutache I, Koressaar T, Ye J, Faircloth BC, Remm M, Rozen SG (2012) Primer3-new capabilities and interfaces. Nucleic acids res 40:e115-e115

Viney R (1970) L'oïdium du Chêne: incident léger ou désastre. Rev For Fr

Viennot-Bourgin G (1968) Note sur les Erysiphacées. Bull Trim Soc Mycol France 84:117-118

Wu B, Hussain M, Zhang W, Stadler M, Liu X, Xiang M (2019) Current insights into fungal species diversity and perspective on naming the environmental DNA sequences of fungi. Mycology 10:127-140 
Xing Z, Zhang L, Wu S, Yi H, Gao Y, Lei Z (2017) Niche comparison among two invasive leafminer species and their parasitoid Opius biroi: implications for competitive displacement. Sci Rep 7:1-6

Yarwood CE (1957) Powdery mildews. Botanical Rev 23:235-301

Yoshida K, Burbano HA, Krause J, Thines M, Weigel D, Kamoun S (2014) Mining herbaria for plant pathogen genomes: back to the future. PLoS Pathogens 10:e1004028
Zheng HD, Zhuang WY (2013) Hymenoscyphus albidoides sp. nov. and $H$. pseudoalbidus from China. Mycol Prog 13:625-638

Publisher's Note Springer Nature remains neutral with regard to jurisdictional claims in published maps and institutional affiliations. 